\title{
Motor-learning based activities may improve functional ability in adults with severe cerebral palsy: A controlled pilot study
}

\author{
Helle Hüche Larsen ${ }^{\mathrm{a}, \mathrm{b}, *}$, Rasmus Feld Frisk ${ }^{\mathrm{a}, \mathrm{b}}$, Maria Willerslev-Olsen ${ }^{\mathrm{a}, \mathrm{b}}$ and Jens Bo Nielsen ${ }^{\mathrm{a}, \mathrm{b}}$ \\ ${ }^{a}$ Department of Neuroscience, University of Copenhagen, Copenhagen, Denmark \\ ${ }^{\mathrm{b}}$ Elsass Foundation, Charlottenlund, Denmark
}

Received 14 September 2020

Accepted 8 December 2020

\begin{abstract}
.
BACKGROUND: Cerebral palsy (CP) is a neurodevelopmental disturbance characterized by impaired control of movement. Function often decreases and $15 \%$ of adults are classified as severely affected (Gross Motor Function Classification Scale III-V). Little is known about interventions that aim to improve functional abilities in this population.

OBJECTIVE: To evaluate a 12-week intervention based on motor learning principles on functional ability in adults with severe CP.

METHODS: 16 adults ( $36 \pm 10$ years, GMFCS III-V) were enrolled and divided into an intervention group (Active group) and a standard care group (Control group). Primary outcome measure was Gross Motor Function Measure (GMFM-88). Secondary measures were neurological status. The Active group were measured at baseline, after the intervention and at one-month follow-up. The Control group were measured at baseline and after one month.

RESULTS: Analysis showed statistically significant improvement in GMFM-88 for the Active group from baseline to post assessment compared with the Control group (group difference: 5 points, SE 14.5, $p=0.008$, CI: 1.2 to 8.7). Improvements were maintained at follow-up. Results from the neurological screening showed no clear tendencies.

CONCLUSIONS: The study provides support that activities based on motor learning principles may improve gross motor function in adults with severe CP.
\end{abstract}

Keywords: Motor learning, motor function, neurorehabilitation, rehabilitation, training, neuroplasticity, cerebral palsy

\section{Introduction}

Cerebral palsy $(\mathrm{CP})$ is a congenital neurodevelopmental disorder caused by a non-progressive

\footnotetext{
*Address for correspondence: Helle Hüche Larsen, Department of Neuroscience, University of Copenhagen, Panum Institute 33.3, Blegdamsvej 3, 2200 Copenhagen, Denmark. Tel.:+45 26573438; E-mail: hhl@elsassfonden.dk.
}

disturbance of the developing brain, which occurs before, at the time of or shortly after birth (Graham et al., 2016; Granild-Jensen, Rackauskaite, Flachs, \& Uldall, 2015). It is the most common type of childhood disability with an estimated prevalence ranging from 1.5 to 2.5 per 1000 live births (Graham et al., 2016; Oskoui, Coutinho, Dykeman, Jette, \& Pringsheim, 2013). Life expectancy in individuals with CP is marginally less than in the general population but 
is closely related to number and severity of associated impairments, such as mental-, motor-, and/or visual impairments. (Colver, Fairhurst, \& Pharoah, 2014; Strauss, Shavelle, Reynolds, Rosenbloom, \& Day, 2007).

Primary impairments include disturbances of movement and posture, which often cause activity limitation as well as disturbances in sensation, perception, cognition, communication and behavior (Graham et al., 2016; Rosenbaum et al., 2007; O. Verschuren, Ketelaar, Takken, Helders, \& Gorter, 2008). The severity of impairments depends on size and location of the lesion and maturational stage of the brain when the lesion occurs (Graham et al., 2016; Rosenbaum et al., 2007). Level of gross motor function is evaluated and categorized from infancy to 15 years of age by the Gross Motor Function Classification System (GMFCS) (Palisano et al., 1997). Severity of impairment varies significantly and can be categorized into 5 different levels of function. GMFCS I indicates minor physical impairments with no real need of assistance whereas individuals in GMFCS V are severely affected with limited mobility and requires daily assistance (Palisano et al., 1997). Around 15\% of adults with CP are categorized in the severely affected groups (S. I. Michelsen, 2017).

Studies have consistently shown that adults with disabilities are at greater risk of leading sedentary lives and that further deterioration of motor performance and risk of developing chronic health conditions is often seen when individuals with $\mathrm{CP}$ reach adulthood (Bottos, Feliciangeli, Sciuto, Gericke, \& Vianello, 2001; Morgan \& McGinley, 2014; Peterson, Ryan, Hurvitz, \& Mahmoudi, 2015; Thorpe, 2009). Adults with CP classified at GMFCS levels IV-V displays fewer breaks interrupting sedentary time and lower levels of light-, moderate-, and vigorous physical activity compared to adults at lower GMFCS levels (Claridge et al., 2015; Olaf Verschuren, Peterson, Balemans, \& Hurvitz, 2016). Additionally, there is significantly higher prevalence of multimorbidities among individuals with GMFCS IV-V compared to individuals at GMFCS I-III (Cremer, Hurvitz, \& Peterson, 2017). Despite of this, only few studies have investigated physical activity interventions in adults with severe CP (Hutzler, Lamela Rodriguez, Mendoza Laiz, Diez, \& Barak, 2013; O. Verschuren et al., 2008). There is a need to identify effective interventions to preserve and improve physical function, reduce loss of functional ability, and alleviate disability throughout the lifespan in adults with severe CP.
Motor learning is described as lasting performance improvements, which reflect functional and structural changes based on the nervous systems ability to reorganize structure, function, and connections in response to stimuli (Dayan \& Cohen, 2011). The idea of plasticity induced motor learning is based on principles derived from basic neuroscience and the understanding of how the central nervous system works. Optimal rehabilitation should therefore include high intensity, long-lasting training with emphasis on active participation. The training should be challenging and progressive and ensure motivation and reward for the individual. Simultaneously, organization of training and consolidation in relation to other activities should be considered (Nielsen, Willerslev-Olsen, Christiansen, LundbyeJensen, \& Lorentzen, 2015). Motor learning and consolidation of new skills appear to be only slightly diminished in adults and elderly compared to children and young adults (Bock \& Schneider, 2002), and previous studies have shown that it is possible to achieve functional improvements in individuals with brain lesions through motor learning (Lorentzen et al., 2015; Lorentzen et al., 2017). Thus, it is reasonable to assume, that adults with severe CP could possibly achieve optimized levels of function through activities based on motor learning principles. The primary aim of the study was to explore whether it is possible to optimize the level of motor function in adults with severe $\mathrm{CP}$ by daily motor-learning based activities. Gross Motor Function Measure (GMFM) was used to investigate this aim. Secondary, data from neurological examination was collected to support the outcomes from the GMFM.

\section{Method}

\subsection{Design}

The study was designed as a controlled, non-randomized pilot study with a 2-group design. Participants were enrolled in the study through convenience sampling by the staff at the care center where the study was performed. Work obligations and other individual challenges that had to be adjusted to the requirements of the training study prevented randomization of the participants.

The Active group underwent a 12-week intervention based on motor learning principles. The Active group was assessed three times in total: Once at baseline, once after the intervention and at 

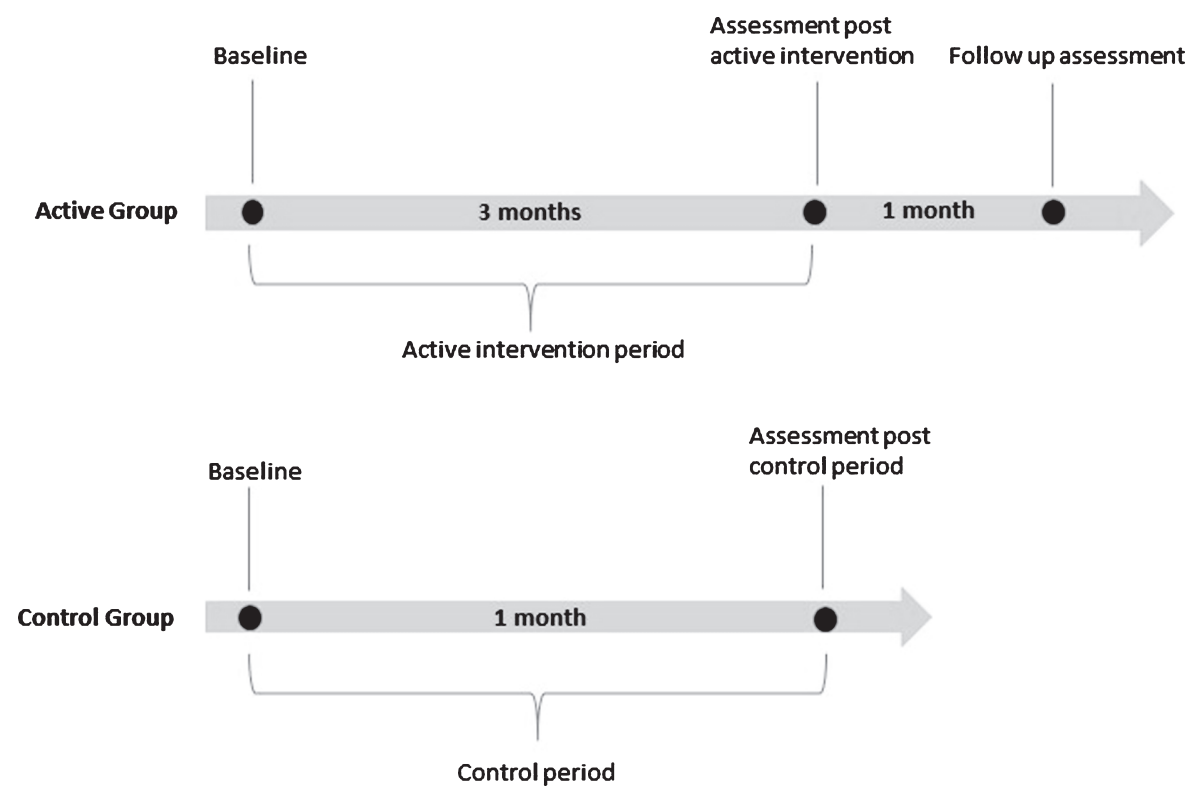

Fig. 1. The Active group was assessed three times: (1) baseline assessment prior to the 12-week active intervention; (2) immediately following the intervention; and (3) one month after finishing the intervention. The Control group was assessed 2 times: (1) baseline assessment prior to the 4-week control period; (2) immediately after the control period.

follow-up one-month after termination of the intervention. The Control group received standard care and was assessed at baseline and follow-up assessment. See Fig. 1 for further information.

\subsection{Ethics and data protection}

All participants provided written informed consent to the study, which was approved by the local ethics committee of the Copenhagen region (No. $\mathrm{H}-18029151)$ and performed in accordance with the Declaration of Helsinki. All personal data was anonymized. Names were assigned to an identification number and files containing personal data were stored on a separate hard drive and stored securely according to the guidelines provided by The Danish Data Protection Agency. The study was registered on www.isrctn.com under identifier ISRCTN66528622.

\subsection{Setting and participants}

Sixteen adult participants diagnosed with severe CP (GMFCS III-V) were recruited from a 24-hour care home in eastern Denmark. All initial contact and information regarding the study was carried out by therapists and caretakers who were in daily contact with the participants. Participants were included if they were clinically diagnosed with $\mathrm{CP},>18$ years of age and had a GMFCS of III-V. Exclusion criteria were previous surgeries involving major restrictions regarding physical activity, uncontrolled seizures or unable to understand simple instructions.

Participants were instructed to continue with existing therapy and leisure activities as usual during the study. All participants were however asked, not to make any major changes such as joining a new sport during the study period. The majority of participants used motorized wheelchairs and had no independent standing or walking function.

There were no significant differences between the two groups in terms of age, height, or weight. All participants in both groups had bilateral CP. In terms of severity of motor impairment both groups included one participant at GMFCS level III and one participant at GMFCS level V, with the remaining participants being at GMFCS level IV. Both groups included more males, however the Active group had a small overweight of females compared to the Control group. The characteristics of the participants are presented in Table 1.

\subsection{Dropouts}

One participant from the Active group experienced a decline in function, which started prior to the onset of the study and escalated further during the study. The participant was later diagnosed with dysplastic 
Table 1

Characteristics of the participants

\begin{tabular}{|c|c|c|c|}
\hline & $\begin{array}{c}\text { Active group } \\
\operatorname{CP}^{\mathrm{c}}(n=9)\end{array}$ & $\begin{array}{l}\text { Control group }{ }^{\mathrm{b}} \\
\operatorname{CP}^{\mathrm{c}}(n=6)\end{array}$ & $p$ \\
\hline $\operatorname{Sex}(m / f)$ & $5 / 4$ & $4 / 2$ & \\
\hline Age (y) & $38 \pm 8$ & $34 \pm 15$ & 0.58 \\
\hline Height (cm) & $160 \pm 9$ & $154 \pm 10$ & 0.27 \\
\hline Weight (kg) & $55 \pm 14$ & $58 \pm 15$ & 0.74 \\
\hline Unilateral $\mathrm{CP}^{\mathrm{d}}$ & 0 & 0 & \\
\hline Bilateral $\mathrm{CP}^{\mathrm{d}}$ & 9 & 6 & \\
\hline \multicolumn{4}{|c|}{ GMFCS level $^{\mathrm{e}}$, (n) } \\
\hline III & 1 & 1 & \\
\hline IV & 7 & 4 & \\
\hline V & 1 & 1 & \\
\hline
\end{tabular}

Data presented as the mean $\pm \mathrm{SD}$. ${ }^{\mathrm{a}}$ Group undergoing motor learning intervention; ${ }^{\mathrm{b}}$ Group with no changes in standard care; ${ }^{\mathrm{c}}$ Cerebral palsy; ${ }^{\mathrm{d}}$ Diagnosis based on clinical evaluation; ${ }^{\mathrm{e}} \mathrm{Gross}$ Motor Function Classification System (GMFCS) level based on self-reported and clinical evaluation.

unilateral hip arthrosis for which he needed a total hip replacement. Due to the circumstances the participant declined a number of assessments together with most of the training sessions due to his condition. It was subsequently decided to remove his results, since the data were not randomly missing. No participants dropped out of the Control group.

\subsection{Discontinuation of medication}

All participants enrolled in the study received antispastic treatment in the form of oral dantrolene, baclofen or both. Six of the participants were planned to be discontinued in antispastic medication as part of their regular treatment. It was on this basis decided to discontinue the medication prior to the intervention as treatment with antispastic medication can cause potential challenges in relation to motor learning (Willerslev-Olsen, Lundbye-Jensen, Petersen, \& Nielsen, 2011). Furthermore, the medication may cause unwanted side effects such as general muscle weakness, sedation, fatigue, and drowsiness (Chang et al., 2013; Goyal, Laisram, Wadhwa, \& Kothari, 2016; Hulme, MacLennan, Ritchie, John, \& Shotton, 1985; Willerslev-Olsen et al., 2011).

The medication was discontinued by $25 \%$ per week during a 4-week period prior to the intervention. In this period participants were closely followed by an experienced physician (JBN).

\subsection{Active intervention based on motor learning principles}

The intervention took place over 12 weeks and was planned based on science-based neurorehabilitation and motor learning principles (10). Prior to the intervention, a workshop was held where caregivers and therapists involved in the study participated. They were introduced to basic principles of neuroplasticity and motor learning along with purpose and general content of the intervention. They were divided into working groups and asked to come up with ideas on how to best integrate training and achieve the goals of the participants into everyday life at the 24-hour care center with the resources available. Additionally, the primary investigator attended a day and an evening shift at the care center to get an impression of the professional life of both caregivers and therapists and the daily routines of the participants.

Participants practiced their goals in a combination of smaller group sessions 3-5 times per week combined with individual training embedded in everyday activities.

Group activities were supervised by the primary investigator and a therapist, pedagogue, or caretaker from the 24-hour care home. Often the group activity would be led by a caretaker enabling the therapist to work with participants and integrate goals into the group training. This could include simplification or progression of a task or verbal, visual, tactile, or auditory cueing.

Group activities would start with an introduction of activities and sometimes wardrobe activities such as putting on clothes to go outside with a special focus for participants with dressing or undressing as goals. Sessions were designed to be fun and social and when possible, the professionals would step aside and encourage participants to help each other solve problems or contribute with ideas to achieve meaningful activities. Sessions often included games on the floor as many participants had crawling or independent turning as a goal. Other sessions would involve playing rhythmic instruments taught by a music teacher. Participants who had bilateral upper extremity goals would play instruments, which required both hands and the degree of difficulty would be adjusted to the individual. Some sessions were held outside in uneven terrain in a nearby forest or street to accommodate the participants with goals related to walking or controlling and steering walking aids.

Individual activities were integrated in everyday activities at the 24-hour care center. They were designed to repeatedly practice the specific goals of the participants through goal-directed activities in relevant surroundings and contexts. These could be activities such as getting dressed, eating independently, turning in bed etc. For one participant, who 
had turning independently in bed as a goal, this would be practiced during group sessions on the floor involving different games, but also imbedded in everyday activities such as getting dressed in bed in the morning or undressed in the evening, getting up for the bathroom at night etc. Caretakers, night watchmen and others were instructed how to facilitate the turning with the least amount of hands on. The participant would keep track of the number of daily repetitions on a scoresheet hanging on the wall and try to beat his own record. Progress would be evaluated every week in terms of level of independence and if necessary, new instructions on facilitation would be generated.

General content and further examples of the motor learning intervention and standard care can be viewed in Fig. 2 according to the Template for Intervention Description and Replication (TIDieR) Checklist (Hoffmann et al., 2014).

In order to provide optimal motor learning, it was essential to tailor each intervention to fit the individual. The participants showed great variation in motor and cognitive difficulties, which had to be taken into consideration. More importantly they had different goals for what they wished to achieve and were motivated by different things. Some were able to take great responsibility of their training, others needed schedules or social support. Although motor learning activities based on principles to induce neuroplasticity apply to a broad spectrum, the practical implementation needs to be adjusted to the individual's specific challenges and everyday life.

\subsection{Training duration}

Compliance to group sessions was at $68 \%$ and frequencies ranged individually from 3 to 5 times per week with a duration of one hour per session. Some training sessions failed to be registered and were considered as failing to attend to prevent overestimation. The most common reasons for not attending was vacation, illness, doctors/dentist appointment and other/unknown.

Individual training was continuously embedded in everyday activities and it was therefore not possible to register participation. Frequency ranged individually from 1 to 4 times a day at changing duration. Most individual training was embedded in morning or evening activities or during transportation or dining.

\subsection{Functional outcomes}

All assessments were performed by two physical therapists (HHL and RF). One therapist conducted the assessments while the other therapist assisted and served as a consultant. To optimize objectivity, none of the measurements below were processed until all assessment rounds were completed. Preventive steps were taken to ensure objectivity such as standardization of assessments and anonymization of participants group allocation and individual data for the data analysist.

\subsubsection{Measurements of gross motor functioning}

Gross Motor Function Measure (GMFM-88) used to assess any changes in gross motor outcome was performed three times alongside neurological screening for the Active group and two times for the Control group.

The GMFM- 88 total score is the most often used to detect changes in gross motor function in a various of interventions and is considered the gold standard (Bleyenheuft, Filipetti, Caldas, \& Lejeune, 2007; Bottos, Benedetti, Salucci, Gasparroni, \& Giannini, 2003; Krach et al., 2005; Nordmark, Jarnlo, \& Hagglund, 2000). The 88 items span the spectrum of gross motor activities in: A: Lying and Rolling, B: Sitting, C: Crawling and Kneeling, D: Standing and, E: Walking, Running and Jumping. Each item is scored using a 4-point ordinal scale ( 0 representing the lowest performance level and 3 the highest level). The score of gross motor function for each participant was evaluated using the Gross Motor Ability Estimator (GMAE 2) to obtain GMFM-88 score ranging from 0-100 on a numerical scale (Russell DJ, 2013).

\subsubsection{Clinical measurements}

Neurological screening was performed alongside with the GMFM-88. Passive range of motion (ROM) of the wrist, elbow, hip, knee, and ankle was evaluated with a goniometer by slowly moving the joint into full flexion and extension. The elbow-, knee, and ankle joints were then examined to evaluate whether catch and/or clonus were present and to evaluate muscle stiffness using the Modified Ashworth Scale (MAS) (Bohannon \& Smith, 1987). Tendon reflex assessment was performed with a reflex hammer of the Bicep tendon, Patella tendon and Achilles tendon using a $0-2$ ordinal grading scale. Voluntary muscle strength in ankle plantar flexion and dorsiflexion, knee flexion and extension, hip flexion and extension, elbow flexion and extension and grip were assessed using a $0-5$ ordinal grading scale (Bickley L, 2013). 


\begin{tabular}{|c|c|c|}
\hline & Standard care & Intervention \\
\hline & Traditional standard care & Activities based on motor learning principles \\
\hline $\begin{array}{l}\frac{\Phi}{\mathbb{D}} \\
\frac{c}{0} \\
\frac{0}{\pi} \\
\frac{1}{\alpha}\end{array}$ & $\begin{array}{l}\text { Elements may include: } \\
\text { 1. Goals defined by patient, caregiver and/or therapist } \\
\text { 2. Functional training consisting of multimodal joint } \\
\text { movements } \\
\text { 3. Facilitation of more normal patterns of movement. } \\
\text { 4. Passive joint movements } \\
\text { 5. Maintenance training } \\
6 . \quad \text { Stretching and/or splinting } \\
\text { 7. Neurodynamic } \\
\text { 8. Strengthening } \\
\text { 9. Positioning } \\
\text { 10. Soft tissue techniques } \\
\text { 11. Sensory integration } \\
\text { 12. Acupuncture } \\
\text { 13. Grounding } \\
\text { 14. Laser and ultrasound } \\
\text { 15. Cardiovascular exercise } \\
\text { 16. Vestibular stimulation } \\
\text { 17. Hippotherapy } \\
\end{array}$ & 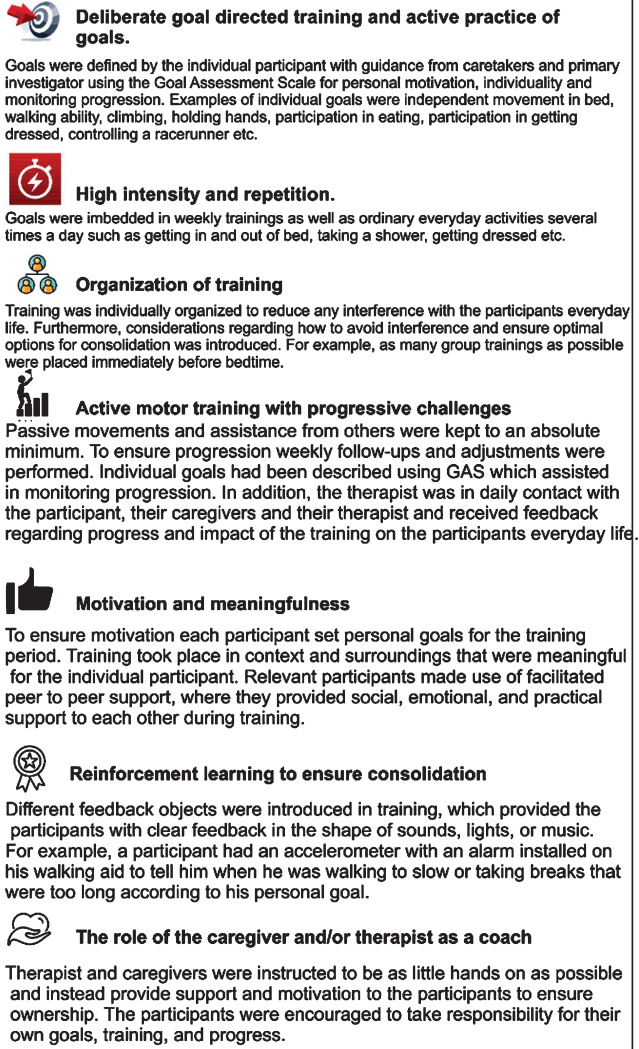 \\
\hline 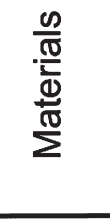 & $\begin{array}{l}\text { Materials may include splints, casts, adaptive equipment, } \\
\text { strength training equipment, stationary bikes, therapy bench, } \\
\text { trampoline, therapy horse etc. }\end{array}$ & $\begin{array}{l}\text { Activities/toys/games/training equipment/music instruments for participants } \\
\text { to actively develop skills with continuous practice of goal-oriented tasks was } \\
\text { used in group activities. Practice of individually identified functional goals } \\
\text { embedded in everyday activities used specific materials related to each goal } \\
\text { to ensure transfer of motor skills to real life. For example, participants would } \\
\text { use their own racerunner, bed, cutlery etc. in training. Individual schedules } \\
\text { with visual training registration were introduced to the participants who } \\
\text { benefitted from this. Descriptions on how to assist the participant in training } \\
\text { specific goals were developed and placed in the individual participants } \\
\text { apartment. }\end{array}$ \\
\hline Who & $\begin{array}{l}\text { Training is carried out by either an occupational therapist or } \\
\text { physiotherapist assigned to the adult. Occasionally training } \\
\text { may be carried out by therapy students who are supervised } \\
\text { by a permanent therapist. }\end{array}$ & $\begin{array}{l}\text { Group activites were carried out by primary investigator together with } \\
\text { caretakers, therapy students or occupational- or physiotherapists. } \\
\text { Activities embedded in everyday life was performed independently by } \\
\text { participants or in combination with caretakers and weekly supervised by } \\
\text { primary investigator. }\end{array}$ \\
\hline How & $\begin{array}{l}\text { Training takes place at the 24-hour care home; often in the } \\
\text { therapy room, the hallways or the individual's apartment. }\end{array}$ & $\begin{array}{l}\text { 24-hour care home; in the therapy room, the hallways, individual apartments, } \\
\text { nearby streets, nearby forest, and approximately } 6 \text { times at a climbing center } \\
\text { outside the premises. }\end{array}$ \\
\hline Dose & $\begin{array}{l}1-2 \text { times weekly. Higly variable and dependent on individual } \\
\text { needs. }\end{array}$ & $\begin{array}{l}12 \text { weeks. Individual training for each participant was embedded in } \\
\text { everyday activities. Frequency ranged individually from } 1 \text { to } 4 \text { times a day at } \\
\text { changing duration. Group training of one-hour duration took place } 3-5 \text { times } \\
\text { a week. }\end{array}$ \\
\hline Tailoring & $\begin{array}{l}\text { May be generic, but highly variable and dependent on } \\
\text { individual needs assesed by the individual therapist. }\end{array}$ & $\begin{array}{l}\text { Training was tailored to the participants individually defined functional goals. } \\
\text { Weekly review of progress to continually and incrementally increase the } \\
\text { challenge was provided. }\end{array}$ \\
\hline $\begin{array}{l}\text { Moni- } \\
\text { toring }\end{array}$ & $\begin{array}{l}\text { Functional ability is assesed once a year where The } \\
\text { International Classification of Functioning, Disability and } \\
\text { Health (ICF) is performed along with a personal plan and } \\
\text { physiotherapeutic goals. }\end{array}$ & $\begin{array}{l}\text { Weekly follow-up and individual interviews with participants and caretakers } \\
\text { by primary investigator including daily use of checklists for individual } \\
\text { participants. Description of individual goals through GAS was used to monitor } \\
\text { continuous progress. }\end{array}$ \\
\hline
\end{tabular}

Fig. 2. General content and examples of the motor learning intervention 
A

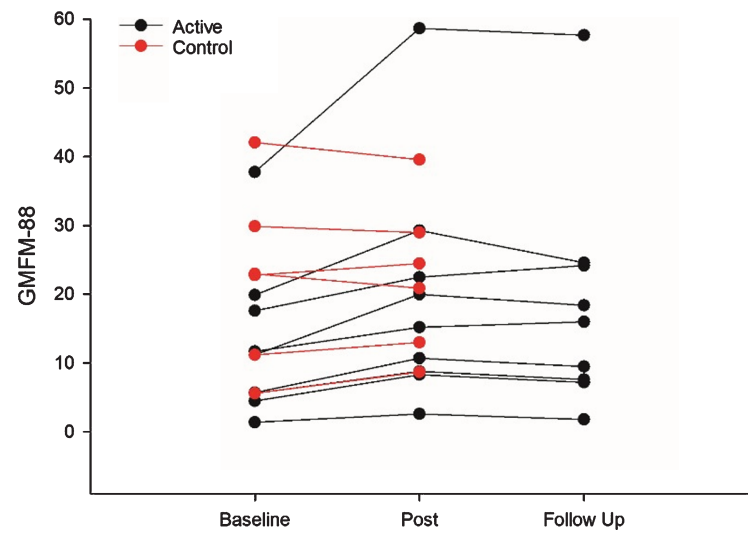

B

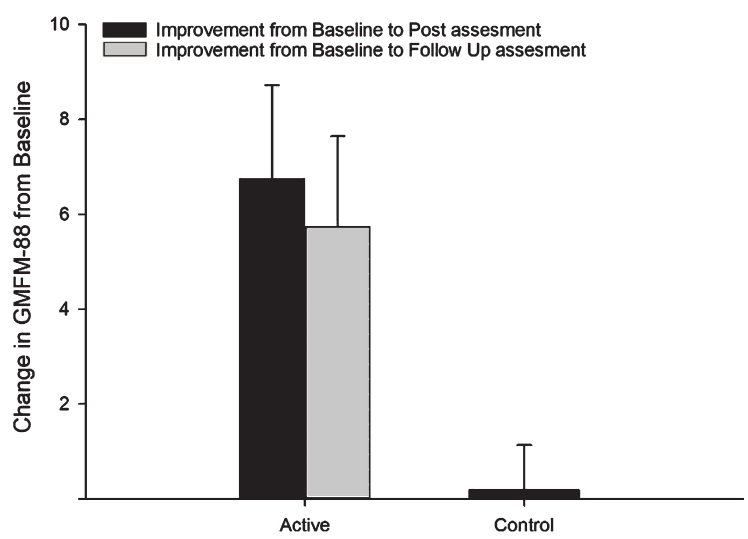

Fig. 3. A. Individual GMFM- 88 scores for all participants from baseline to follow-up. B. Overall change in GMFM- 88 from baseline to post assessment and follow up.

\subsubsection{Integration of individual goals into activities}

Goal Attainment Scaling (GAS) (Kiresuk \& Sherman, 1968; Turner-Stokes, 2009) was performed solely in the Active group to identify individual goals for each participant before planning the intervention. GAS was used solely as a motivational tool to support meaning and ownership and ensure desired progression during the intervention.

The goals were individually identified through interviews in a cooperation between the participant, a close caregiver and primary investigator to enable better integration of the goals into activities of daily living. All participants had their own outcome measure and levels were individually set around their current and expected level of performance and precisely described. Goals had to be realistic within the time period of the intervention but sufficiently above current level of performance to ensure challenge and motivation.

\subsection{Statistical analysis}

GMFM-88 was analyzed using mixed model regression (MIXED) analysis with group and test as factors both on factual measurements and change estimates from baseline to post assessment and from baseline to follow-up, respectively. Using this model, all available data was included in the analysis in case of unbalanced datasets between the groups. Data was tested for normality using Shapiro-Wilk test, histograms and QQ plots.

In the post-hoc pairwise comparison Tukey adjustments was applied to reduce the risk of type I errors due to multiple comparisons when analyzing the GMFM-88. Results from the MIXED regression analysis are presented as mean differences with stand error (SE) and $95 \%$ confidence intervals. The level of significance was 0.05 .

Modified Ashworth Scale, tendon reflex score and 0-5 strength score are all ordinal data. They are all presented as pooled medians and 25 th and 75 th centiles for respectively upper- and lower extremity.

ROM is scored on a ratio scale and data is presented as mean and standard deviation for reduction in range of motion in each joint.

MAS, 0-5 strength, tendon reflex, and ROM are based on available assessments whereas the MIXED regression analysis consider missing data. All nonparametric statistics are presented as median, 25th and 75 th centiles. The statistical tests were carried out in SAS 9.4. Figures were conducted using SigmaPlot 13.0.

\section{Results}

\subsection{Training effect}

Individual plots of the assessments show clear tendencies of improved performance in GMFM- 88 from baseline to follow up in the Active group whereas the participants in the Control group did not (Fig. 3A). The mixed model regression analysis did show that either test $\left(\mathrm{F}_{0.16}=15,4 p=0.85\right)$ or the interaction between test and group $\left(\mathrm{F}_{1.64}=14,7 p=0.23\right)$ were significant factors.

However, using change estimates from baseline to post assessment and follow up, respectively, the 
regression analysis showed group as significant factor $\left(\mathrm{F}_{11.75}=17 p=0.003\right)$. The post hoc analysis showed statistically significant improvement in GMFM-88 in the participants in the Active group from baseline to post assessment compared with the Control group (group difference: 5 points, SE $14.5, p=0.008, \mathrm{CI}: 1.2$ to 8.7 ). Additionally, there was only minor difference in the change estimates from baseline to post assessment and from baseline to follow up in the Active group (1.3 points, SE 1.4, $p=0.64$, CI: -2.3 to 4.9 ). This reflects that the participants in the Active group maintained their improvements on GMFM- 88 as also shown on Fig. 3B.

Most of the included participants were able to be tested in dimension A and B of the GMFM regarding gross motor function in lying and rolling (A) and in sitting (B), which supports that they had a GMFS level of IV or V with limited functional independence. All participants improved motor performance in dimension A and B except one participant which scored little less in section B during the post assessment. Three participants managed to improve their gross motor function to a degree which made them able to continue to the next section during the post assessments (one participant from dimension $\mathrm{A}$ to $\mathrm{B}$ and two participants from dimension $\mathrm{B}$ to $\mathrm{C}$ ). The few participants that were able to be tested in dimension $\mathrm{C}, \mathrm{D}$ and $\mathrm{E}$ ( 3 in the Active group and 3 in the Control group), were able to stand with support.

\subsection{Neurological screening}

No clear tendencies were observed over time in neither MAS nor strength measurements. ROM showed great variability within the groups; however, no clear change was observed. Summary of MAS, strength and ROM measurements can be found in supplementary materials (Supplementary Tables 1-4).

\section{Discussion}

The present study is to the best of our knowledge the first to examine whether functional abilities may be improved by goal-directed activities based on motor learning principles in adults with severe $\mathrm{CP}$.

\subsection{Improvements in gross motor function}

The mixed model regression analysis of the GMFM-88 results showed no significant difference between the two groups although a clear tendency for improved performance as measured by GMFM- 88 was seen in the Active group. The lack of significance despite an average increase in GMFM- 88 of 5 points is in all likelihood due to the small sample and large variation at baseline between the participants. Indeed, when using change estimates, a significant group difference was found. Direct comparison of the GMFM-88 scores with that of other studies is challenging because of the wide variation in sample characteristics. In addition, most studies in which GMFM- 88 has been used, have been performed in children where age and developmental changes in the course of the study are confounding factors (Ammann-Reiffer, Bastiaenen, Meyer-Heim, \& van Hedel, 2017; Franki et al., 2015; Williams \& Pountney, 2007). Nevertheless, an increase of 3.99 points is considered clinically important and our observation of an average increase of 5 points, therefore, is not negligible (Wang \& Yang, 2006).

The present study was not designed to investigate the effect of the training intervention in the different dimensions of the GMFM as the intervention was planned for each individual participant based on their functional level. Therefore, statistical analysis addressing such question has not been performed. Such an investigation/analysis would have needed a much more standardized training intervention and a larger number of participants with equal distribution of GMFCS levels in each group.

\subsubsection{Activities based on motor learning principles in adults with severe $C P$}

Since several different motor learning principles were applied as part of the intervention in the present study, it is not possible to determine to which extent each of them contributed to the overall functional effect of the intervention. The intervention was tailored the way it was in the belief that the combination of the different principles is more effective than applying and investigating each of the principles in isolation. Also, this approach reflects everyday rehabilitation to a greater extent where practitioners are more likely to apply several approaches and are unable to control the environment and all treatment circumstances. An investigation of each principle isolated may be inadequate to take the heterogeneity and complexity of this population into consideration.

Knowledge from basic science regarding plasticity underlying motor learning provides a useful framework for future neurorehabilitation and many principles have already been applied more or less intentionally into rehabilitation in different types 
of training, therapy, and concepts. However, therapeutic procedures must avoid becoming rigid and conceptualized and future approaches should provide customized treatment options supported by a solid scientific foundation.

\subsection{Outcome measurements}

The GMFM- 88 has only been validated for children with CP up to the age of 16 years and was therefore chosen in the absence of validated measurement methods for the study population. The GMFM-88 has many advantages when assessing a group as diverse in gross motor function skills as the participants in this study. The 88 items examine lying, rolling, sitting, crawling, kneeling, standing, walking, running, and jumping. Due to the large number of items in the lying and rolling dimension the measurement was sensitive to detecting change in the most severely affected participants and still able to include the participants at GMFCS level III without any risk of ceiling effect. The majority of measurements developed for adults with functional disabilities are addressed to persons with stroke and tend to focus on the affected versus the non-affected side, which would not be optimal in this study as all participant are quadriplegic.

Despite the lack of validation, the GMFM- 88 total score is considered the gold standard to detect changes in gross motor function in various interventions (Bleyenheuft et al., 2007; Bottos et al., 2003; Krach et al., 2005; Nordmark et al., 2000) and has previously been used as assessment tool for adults with CP (Andersson, Grooten, Hellsten, Kaping, \& Mattsson, 2003; Slaman et al., 2015).

\subsection{Daily training in severely affected individuals with $\mathrm{CP}$ is feasible}

Importantly, this study demonstrated that it was possible to keep the participants active and motivated for the entire training period by combining social group sessions with individualized training and making the sessions fun and challenging. The caregivers at the 24-hour care home played a very active part in the individual everyday training imbedded in everyday activities, which encouraged the participants.

No adverse events occurred except for occasionally muscle soreness, fatigue and a few skin abrasions which was to be expected and was well handled by the participants. Subjective feedback from caregivers, therapist and participants was predominantly positive and the increased level of daily physical activity was very well received.

\subsection{Limitations}

The study has several limitations such as small sample size, insufficient control, and lack of randomization. The small sample size combined with the main part of the participants being at GMFCS level IV precluded any exploration of subgroup responsiveness to the intervention. Larger future studies may consider preplanned subgroup analysis to efficiently evaluate the effect of the intervention. In addition, participants were enrolled through convenience sampling and were not randomly assigned to the control or intervention group. Therefore, selection bias may have occurred, and the result may not be representative for the population.

Furthermore, even though the GMFM-88 has many advantages and is currently the optimal measurement alternative, it may not be suitable and other measurement methods should be developed and validated for the population.

Six out of nine participants in the Active group were discontinued in oral antispastic medication immediately prior to the intervention to create optimal conditions for motor learning. It is impossible to establish whether the discontinuation had any influence on the outcome of the intervention. This is further complicated by the fact, that the participants were discontinued by different amounts of antispastic medication.

In this study MAS was used as a screening tool to evaluate spasticity and no clear differences were observed. However, several studies have shown MAS to be unreliable to discriminate between lower scores (Kirk et al., 2016) and insufficient in distinguishing spasticity from changes in passive muscle properties (Dietz \& Sinkjaer, 2007; Lorentzen et al., 2010). A previous study has shown that more than one third of patients treated with antispastic medication did in fact not have pathologically increased reflex-mediated stiffness but rather changes in passive muscle properties (Lorentzen et al., 2010). Whether this was the case with any of the participants in this study remains unknown.

\section{Conclusion}

The study provides preliminary support that activities based on motor learning principles may possibly improve motor function in adults with severe CP. The 
study prepares the foundation for future studies to investigate the effect of neuroplastic principles integrated in rehabilitation as well as the impact of motor learning principles in this population. We encourage that larger randomized controlled trials are initiated in order to document this.

\section{Acknowledgments}

The authors are very grateful to the participants, caregivers and therapists who participated in this study for their enthusiasm, extra hours, and patience.

\section{Conflict of interest}

The authors declare that no competing interests exist.

\section{Supplementary files}

The supplementary tables are available from https://dx.doi.org/10.3233/NRE-201581.

\section{References}

Ammann-Reiffer, C., Bastiaenen, C. H., Meyer-Heim, A. D., \& van Hedel, H. J. (2017). Effectiveness of robot-assisted gait training in children with cerebral palsy: a bicenter, pragmatic, randomized, cross-over trial (PeLoGAIT). BMC Pediatr, 17(1), 64. doi:10.1186/s12887-017-0815-y

Andersson, C., Grooten, W., Hellsten, M., Kaping, K., \& Mattsson, E. (2003). Adults with cerebral palsy: walking ability after progressive strength training. Developmental Medicine \& Child Neurology, 45(4), 220-228.

Bickley L, S., PG.. (2013). Bates' guide to physical examination and history taking (11th ed.). Philadelpheia: Lippincott Williams \& Wilkins.

Bleyenheuft, C., Filipetti, P., Caldas, C., \& Lejeune, T. (2007). Experience with external pump trial prior to implantation for intrathecal baclofen in ambulatory patients with spastic cerebral palsy. Neurophysiol Clin, 37(1), 23-28. doi:10.1016/ j.neucli.2007.01.004

Bock, O., \& Schneider, S. (2002). Sensorimotor adaptation in young and elderly humans. Neurosci Biobehav Rev, 26(7), 761-767.

Bohannon, R. W., \& Smith, M. B. (1987). Interrater reliability of a modified Ashworth scale of muscle spasticity. Phys Ther, 67(2), 206-207. doi:10.1093/ptj/67.2.206

Bottos, M., Benedetti, M. G., Salucci, P., Gasparroni, V., \& Giannini, S. (2003). Botulinum toxin with and without casting in ambulant children with spastic diplegia: a clinical and functional assessment. Dev Med Child Neurol, 45(11), 758-762.
Bottos, M., Feliciangeli, A., Sciuto, L., Gericke, C., \& Vianello, A. (2001). Functional status of adults with cerebral palsy and implications for treatment of children. Dev Med Child Neurol, 43(8), 516-528.

Chang, E., Ghosh, N., Yanni, D., Lee, S., Alexandru, D., \& Mozaffar, T. (2013). A Review of Spasticity Treatments: Pharmacological and Interventional Approaches. Crit Rev Phys Rehabil Med, 25(1-2), 11-22. doi:10.1615/CritRevPhysRehabilMed. 2013007945

Claridge, E. A., McPhee, P. G., Timmons, B. W., Martin Ginis, K. A., Macdonald, M. J., \& Gorter, J. W. (2015). Quantification of Physical Activity and Sedentary Time in Adults with Cerebral Palsy. Medicine \& Science in Sports \& Exercise, 47(8), 17191726. doi:10.1249/MSS.0000000000000589

Colver, A., Fairhurst, C., \& Pharoah, P. O. (2014). Cerebral palsy. Lancet, 383(9924), 1240-1249. doi:10.1016/s0140-6736(13) 61835-8

Cremer, N., Hurvitz, E. A., \& Peterson, M. D. (2017). Multimorbidity in Middle-Aged Adults with Cerebral Palsy. Am J Med, 130(6), 744.e749-744.e715. doi:10.1016/j.amjmed.2016.11. 044

Dayan, E., \& Cohen, L. G. (2011). Neuroplasticity subserving motor skill learning. Neuron, 72(3), 443-454. doi:10.1016/ j.neuron.2011.10.008

Dietz, V., \& Sinkjaer, T. (2007). Spastic movement disorder: impaired reflex function and altered muscle mechanics. Lancet Neurol, 6(8), 725-733. doi:10.1016/s1474-4422(07)70193-x

Franki, I., Desloovere, K., De Cat, J., Tijhuis, W., Molenaers, G., Feys, H.,... Van Den Broeck, C. (2015). An evaluatorblinded randomized controlled trial evaluating therapy effects and prognostic factors for a general and an individually defined physical therapy program in ambulant children with bilateral spastic cerebral palsy. Eur J Phys Rehabil Med, 51(6), 677-691.

Goyal, V., Laisram, N., Wadhwa, R. K., \& Kothari, S. Y. (2016). Prospective Randomized Study of Oral Diazepam and Baclofen on Spasticity in Cerebral Palsy. J Clin Diagn Res, 10(6), Rc01-05. doi:10.7860/jcdr/2016/17067.7975

Graham, H. K., Rosenbaum, P., Paneth, N., Dan, B., Lin, J. P., Damiano, D. L.,... Lieber, R. L. (2016). Cerebral palsy. Nat Rev Dis Primers, 2, 15082. doi:10.1038/nrdp.2015.82

Granild-Jensen, J. B., Rackauskaite, G., Flachs, E. M., \& Uldall, P. (2015). Predictors for early diagnosis of cerebral palsy from national registry data. Dev Med Child Neurol, 57(10), 931-935. doi:10.1111/dmen.12760

Hoffmann, T. C., Glasziou, P. P., Boutron, I., Milne, R., Perera, R., Moher, D.,... Michie, S. (2014). Better reporting of interventions: template for intervention description and replication (TIDieR) checklist and guide. Bmj, 348, g1687. doi:10.1136/bmj.g1687

Hulme, A., MacLennan, W. J., Ritchie, R. T., John, V. A., \& Shotton, P. A. (1985). Baclofen in the elderly stroke patient its side-effects and pharmacokinetics. Eur J Clin Pharmacol, 29(4), 467-469.

Hutzler, Y., Lamela Rodriguez, B., Mendoza Laiz, N., Diez, I., \& Barak, S. (2013). The effects of an exercise training program on hand and wrist strength, and function, and activities of daily living, in adults with severe cerebral palsy. Res Dev Disabil, 34(12), 4343-4354. doi:10.1016/j.ridd.2013.09.015

Kiresuk, T. J., \& Sherman, R. E. (1968). Goal attainment scaling: A general method for evaluating comprehensive community mental health programs. Community Ment Health J, 4(6), 443453. doi:10.1007/bf01530764 
Kirk, H., Geertsen, S. S., Lorentzen, J., Krarup, K. B., Bandholm, T., \& Nielsen, J. B. (2016). Explosive Resistance Training Increases Rate of Force Development in Ankle Dorsiflexors and Gait Function in Adults With Cerebral Palsy. $J$ Strength Cond Res, 30(10), 2749-2760. doi:10.1519/jsc.0000 000000001376

Krach, L. E., Kriel, R. L., Gilmartin, R. C., Swift, D. M., Storrs, B. B., Abbott, R.,... Nadell, J. M. (2005). GMFM 1 year after continuous intrathecal baclofen infusion. Pediatr Rehabil, 8(3), 207-213. doi:10.1080/13638490400021479

Lorentzen, J., Greve, L. Z., Kliim-Due, M., Rasmussen, B., Bilde, P. E., \& Nielsen, J. B. (2015). Twenty weeks of home-based interactive training of children with cerebral palsy improves functional abilities. BMC Neurol, 15, 75. doi:10.1186/s12883015-0334-0

Lorentzen, J., Grey, M. J., Crone, C., Mazevet, D., BieringSorensen, F., \& Nielsen, J. B. (2010). Distinguishing active from passive components of ankle plantar flexor stiffness in stroke, spinal cord injury and multiple sclerosis. Clin Neurophysiol, 121(11), 1939-1951. doi:10.1016/j.clinph.2010. 02.167

Lorentzen, J., Kirk, H., Fernandez-Lago, H., Frisk, R., Scharff Nielsen, N., Jorsal, M., \& Nielsen, J. B. (2017). Treadmill training with an incline reduces ankle joint stiffness and improves active range of movement during gait in adults with cerebral palsy. Disabil Rehabil, 39(10), 987-993. doi:10.1080/ 09638288.2016.1174745

Morgan, P., \& McGinley, J. (2014). Gait function and decline in adults with cerebral palsy: a systematic review. Disabil Rehabil, 36(1), 1-9. doi:10.3109/09638288.2013.775359

Nielsen, J. B., Willerslev-Olsen, M., Christiansen, L., LundbyeJensen, J., \& Lorentzen, J. (2015). Science-based neurorehabilitation: recommendations for neurorehabilitation from basic science. J Mot Behav, 47(1), 7-17. doi:10.1080/00222895. 2014.931273

Nordmark, E., Jarnlo, G. B., \& Hagglund, G. (2000). Comparison of the Gross Motor Function Measure and Paediatric Evaluation of Disability Inventory in assessing motor function in children undergoing selective dorsal rhizotomy. Dev Med Child Neurol, 42(4), 245-252.

Oskoui, M., Coutinho, F., Dykeman, J., Jette, N., \& Pringsheim, T. (2013). An update on the prevalence of cerebral palsy: a systematic review and meta-analysis. Dev Med Child Neurol, 55(6), 509-519. doi:10.1111/dmen.12080

Palisano, R., Rosenbaum, P., Walter, S., Russell, D., Wood, E., \& Galuppi, B. (1997). Development and reliability of a system to classify gross motor function in children with cerebral palsy. Dev Med Child Neurol, 39(4), 214-223.

Peterson, M. D., Ryan, J. M., Hurvitz, E. A., \& Mahmoudi, E. (2015). Chronic Conditions in Adults With Cerebral Palsy. Jama, 314(21), 2303-2305. doi:10.1001/jama.2015.11025
Rosenbaum, P., Paneth, N., Leviton, A., Goldstein, M., Bax, M., Damiano, D.,... Jacobsson, B. (2007). A report: the definition and classification of cerebral palsy April 2006. Dev Med Child Neurol Suppl, 109, 8-14.

Russell DJ, R. P., Wright M, Lane M. (2013). Gross Motor Function Measure (GMFM-66 and GMFM-88) User's manual (2nd edition ed.): Mac Keith Press.

S. I. Michelsen, B. L., E. M. Flachs, I Voss, P Due, P Uldall. (2017). Voksne med cerebral parese i Danmark

Retrieved from Statens Institut for Folkesundhed, SDU

Slaman, J., van den Berg-Emons, H. J., van Meeteren, J., Twisk, J., van Markus, F., Stam, H. J.,... Roebroeck, M. E. (2015). A lifestyle intervention improves fatigue, mental health and social support among adolescents and young adults with cerebral palsy: focus on mediating effects. Clin Rehabil, 29(7), 717-727. doi:10.1177/0269215514555136

Strauss, D., Shavelle, R., Reynolds, R., Rosenbloom, L., \& Day, S. (2007). Survival in cerebral palsy in the last 20 years: signs of improvement? Dev Med Child Neurol, 49(2), 86-92. doi:10.1111/j.1469-8749.2007.00086.x

Thorpe, D. (2009). The role of fitness in health and disease: status of adults with cerebral palsy. Developmental Medicine \& Child Neurology, 51, 52-58. doi:10.1111/j.1469-8749.2009.03433.x

Turner-Stokes, L. (2009). Goal attainment scaling (GAS) in rehabilitation: a practical guide. Clin Rehabil, 23(4), 362-370. doi: $10.1177 / 0269215508101742$

Verschuren, O., Ketelaar, M., Takken, T., Helders, P. J., \& Gorter, J. W. (2008). Exercise programs for children with cerebral palsy: a systematic review of the literature. Am J Phys Med Rehabil, 87(5), 404-417. doi:10.1097/PHM.0b013e31815b2675

Verschuren, O., Peterson, M. D., Balemans, A. C. J., \& Hurvitz, E. A. (2016). Exercise and physical activity recommendations for people with cerebral palsy. Developmental Medicine \& Child Neurology, 58(8), 798-808. doi:10.1111/dmcn.13053

Wang, H. Y., \& Yang, Y. H. (2006). Evaluating the responsiveness of 2 versions of the gross motor function measure for children with cerebral palsy. Arch Phys Med Rehabil, 87(1), 51-56. doi:10.1016/j.apmr.2005.08.117

Willerslev-Olsen, M., Lundbye-Jensen, J., Petersen, T. H., \& Nielsen, J. B. (2011). The effect of baclofen and diazepam on motor skill acquisition in healthy subjects. Exp Brain Res, 213(4), 465-474. doi:10.1007/s00221-011-2798-5

Williams, H., \& Pountney, T. (2007). Effects of a static bicycling programme on the functional ability of young people with cerebral palsy who are non-ambulant. Dev Med Child Neurol, 49(7), 522-527. doi:10.1111/j.1469-8749.2007.00522.x 